УДК $33: 69: 004(510)$

\title{
ДИНАМИКА РАЗВИТИЯ МИРОВОГО СТРОИТЕЛЬНОГО РЫНКА В РАЗРЕЗЕ ЗАТРАТ НА СТРОИТЕЛЬСТВО, ДОЛЕЙ ОТРАСЛИ В МИРОВОЙ ЭКОНОМИКЕ, РЕЙТИНГА РЕГИОНОВ
}

\author{
И. В. Мальцевич 1
}

${ }^{1}$ Аспирант ГНУ «Институт экономики НАН Беларуси», Минск, Беларусь, e-mail: miv1995@mail.ru

\begin{abstract}
Реферат
Проведен анализ перспектив развития строительной отрасли до 2035 года и исследования особенностей развития мирового строительного рынка за 1970-2019 годы в контексте становления экономики и использования инноваций. По рейтингу стран в строительстве за 2019 год по регионам распределение следующее: Азия - 43,8 \%, Америка - 27,7 \%, Европа - 22,9 \%, Африка - 3,2 \%, Океания - 2,4 \%. Акцент по рейтингу в строительной отрасли сместился в регионы Азии и Америки и поэтому особенно актуальным остается вопрос использования в Китае цифровых технологий, предусматривающих использование современных материалов и технологий будущего. Целью исследований является изучение динамики развития мирового строительного рынка в разрезе затрат на строительство, долей отрасли в мировой экономике, рейтинга регионов.
\end{abstract}

Ключевые слова: строительство в мире, затраты,статистика, рейтинг, инновации.

\section{DYNAMICS OF DEVELOPMENT OF THE WORLD CONSTRUCTION MARKET IN THE CASE OF CONSTRUCTION COSTS, SHARES OF THE INDUSTRY IN THE WORLD ECONOMY, REGIONAL RATING}

\begin{abstract}
I. V. Maltsevich
Abstract

The analysis of the prospects for the development of the construction industry until 2035 and the study of the features of the development of the world construction market for 1970-2019 in the context of the formation of the economy and the use of innovations. According to the rating of countries in construction for 2019 , the distribution by regions is as follows: Asia $-43.8 \%$, America $-27.7 \%$, Europe $-22.9 \%$, Africa - 3.2 \%, Oceania - $2.4 \%$. The focus of the rating in the construction industry has shifted to the regions of Asia and America and therefore the issue of using digital technologies in China, providing for the use of modern materials and technologies of the future, remains especially relevant. The aim of the research is to study the dynamics of the development of the world construction market in the context of construction costs, the share of the industry in the world economy, and the rating of regions.
\end{abstract}

Key words: construction in the world, costs, statistics, rating, innovation

\section{Введение}

Анализ перспектив развития строительной отрасли показывает ее стратегическое значение для мировой экономики. Она относится к числу фондообразующих отраслей, позволяет улучшить ситуацию на рынке и положительно влияет на экономическую и социальную ситуацию в обществе. Конкурентоспособность строительной отрасли зависит от устойчивого инновационного функционирования, обеспечивающего выпуск конкурентоспособной качественной строительной продукции на внутреннем и внешних рынках.

Перспективные направления - повышение инвестиционной привлекательности строительства и рост экспорта строительных услуг, качества выполняемых строительных работ (услуг) и внедрение принципов «зеленого» строительства, цифровая транссрормация строительного комплекса и усиление кадрового потенциала в строительной сфрере.

Экономическое развитие стран на уровне мировой экономики планируется на средне- и долгосрочную перспективу (краткосрочная перспектива - создание новых рабочих мест, среднесрочная и долгосрочная перспектива - ускорение темпов экономического роста, снижение транспортных издержек и улучшение качества жизни населения). По оценкам McKinsey Global Institute, прирост инвестиций в инфраструктуру величиной в $1 \%$ ВВП создаст 3,4 млн новых рабочих мест в Индии 1,5 млн мест - в США или 1,3 млн - в Бразилии. Минимальная потребность в инфраструктурных инвестициях составляет 57-67 трлн долл. в период 2013-2030 гг. (в среднем 3,4-3,9 трлн долл. в год). Эта оценка основана на историческом объеме инвестиций в инфрраструктуру за последние 18 лет на уровне 3,5-3,8 \% от ВВП. Направления строительной отрасли в мире будут развиваться с технологической модернизацией промышленных отраслей, ростом населения, урбанизацией.

Развитие строительной отрасли в промышленности будет определяться ее потребностями. Жилищное строительство проходит сложный период развития. Конъюнктура рынка и негативные тенденции (мировые экономические кризисы последних лет, ипотечный кризис в США, завершение среднесрочных инвестиционных циклов в некоторых развитых странах) вызвали спад ввода жилых домов в развитых и развивающихся странах, в том числе лидеров по строительству (США, Китай, Германия). Социальная значимость, демографическая ситуация и мировые социально-экономические тенденции обуславливают циклический характер развития отрасли и ее перспективы развития.

Динамика развития строительной отрасли показывает ее трансформацию на мировом рынке, основанную на отказе от традиционных методов проектирования и строительства в пользу использования цифровых технологий. По различным оценкам размер цифрровой экономики составляет 4,5-15,5 \% ВВП. Развитые страны реализуют проекты Индустрия 4,0 (Германия), Общество 5,0 (Япония и др.), направленные на цифровизацию экономики. В мировом секторе на информационно-коммуникационные технологии около $40 \%$ добавленной стоимости приходится на Китай и США. Во всех странах возрастает количество компьютерных услуг, обеспечивая занятость в секторе информационно-коммуникационных технологий [1].

Важнейшим требованием цифровизации отрасли является разработка научно обоснованного процесса изменений в целевой фокусировке обеспечения эффективной системной реализации инвестиционных инициатив в строительстве. Актуальность иследований обусловлена трендом развития мировой экономики в условиях цифровой трансформации строительной отрасли.

Цель работы: изучение динамики развития мирового строительного рынка в разрезе затрат на строительство, долей отрасли в мировой экономике, рейтинга регионов. 
Вестник Брестского государственного технического университета. 2021

\section{Перспективы развития мирового строительного рынка до 2035 года}

Изменение конъюнктуры объемов мировой экономики обуславливает перспективы развития мирового строительного рынка. Эксперты Global Construction Perspectives и Oxford Economics отмечают, что к 2030 году на 85 \% по сравнению с 2016 годом увеличится объем мирового строительного сектора составит 17,5 трлн долл. США, что основано на продолжающейся индустриализации национальных экономик стран Юго-Восточной Азии и восстановления экономики США, после резкого спада в период финансового кризиса. Строительный мировой рынок будет расти более быстрыми темпами, чем объем изменения мирового ВВП в сторону строительных рынков Юго-Восточной Азии и других стран с развивающимися экономиками, где рост населения, быстрая урбанизация и высокие темпы экономического роста станут основными драйверами для строительства.

На рисунке 1 приведена сводная информация об оценках международных экспертов тенденций развития мирового строительного рынка по прогнозам Oxford Economics [2].

По прогнозам до 2030 года ожидается положительная тенденция роста мирового строительного рынка (удельный вес строительной отрасли в общем объеме мирового ВВП планируется увеличить до 14,7 \%). С учетом развития национальных экономик предполагается перспективный рост в странах Юго-Восточной Азии (Индонезия, Вьетнам, Филиппины и др.) за счет реализации инфраструктурных проектов. По прогнозам к 2025 г. в мире доля китайских строительных корпораций составит $25 \%$ от всего объема строительных контрактов. Индонезия, Вьетнам и Филиппины существенно выиграют от расширения межрегиональной торговли с КНР и прочими соседними экономиками, что вызовет необходимость инвестиций в строительство новых производственных мощностей.
Страны Африки южнее Сахары (Нигерия, Гана, Камерун, Судан) станут вторым регионом мира к 2025 г. по темпам роста объемов строительного рынка за счет увеличения численности населения (по сравнению с сегодняшним днем) на 40 \% (1,2 млрд человек). Необходимость строительства жилья, объектов городской инфрраструктуры, медицинских и учебных заведений будет обусловлена урбанизацией в регионе.

Неустойчивый характер на строительные услуги предполагается в странах Ближнего и Среднего Востока (ОАЭ, Саудовская Аравия, Кувейт) в зависимости от колебаний конъюнктуры мирового нефттного рынка и геополитической ситуации в регионе. В Катаре возможны исключения (предполагается возведение объектов спортивной инфраструктуры для проведения чемпионата FIFA в 2022 году). Дисбаланс в развитие строительства в этом регионе возможен из-за геополитической напряжённости.

В странах Латинской и Южной Америки (Эквадор, Перу и др.) строительный рынок будет медленнее (около 3-4 \% в год), чем в среднем в мире в долгосрочной перспективе, что объясняется высокими ставками налогов, бюрократией в органах государственного управления, снижением цены на нефть и нефтепродукты (непростая ситуация будет складываться в Венесуэле, которая в 2017 году испытывает значительные трудности с внешним долгом). За счет ввода новых производственных мощностей в горнодобывающей промышленности будет поддерживаться активность строительного сектора в ряде стран региона (Чили, Колумбия). Выход на жилищный рынок Латинской Америки возможен для строительных кампаний, предоставляющих инновационные решения по возведению доступного жилья экономкласса, поскольку почти 60 млн человек живут в непригодных для жилья домах.

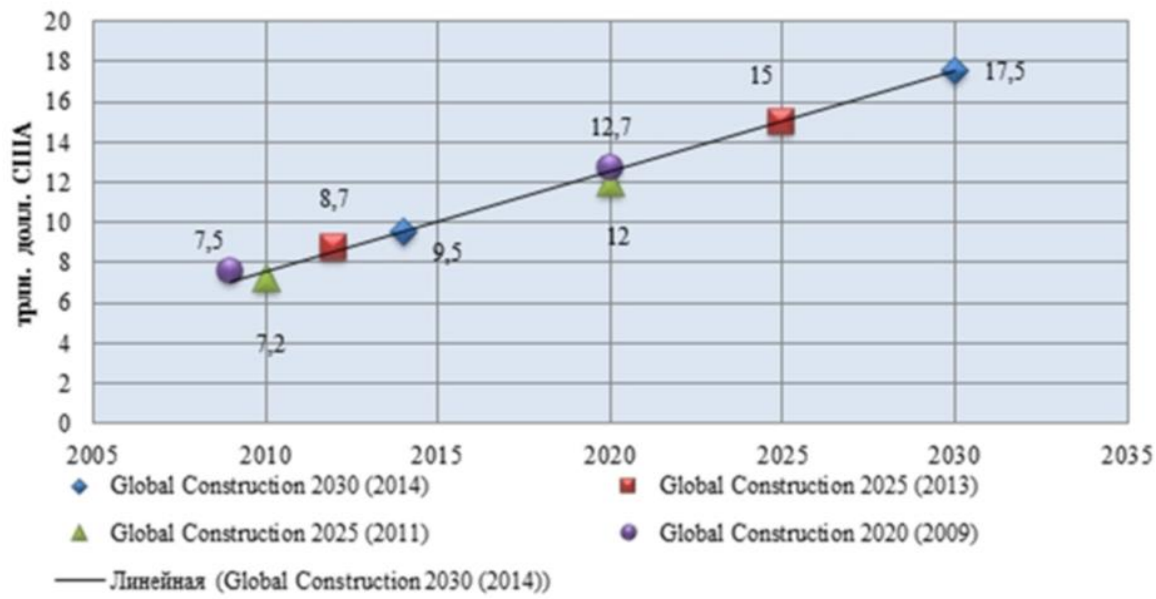

Рисунок 1 - Прогнозы изменения объемов развития мирового строительного рынка (экспертная оценка) [2].

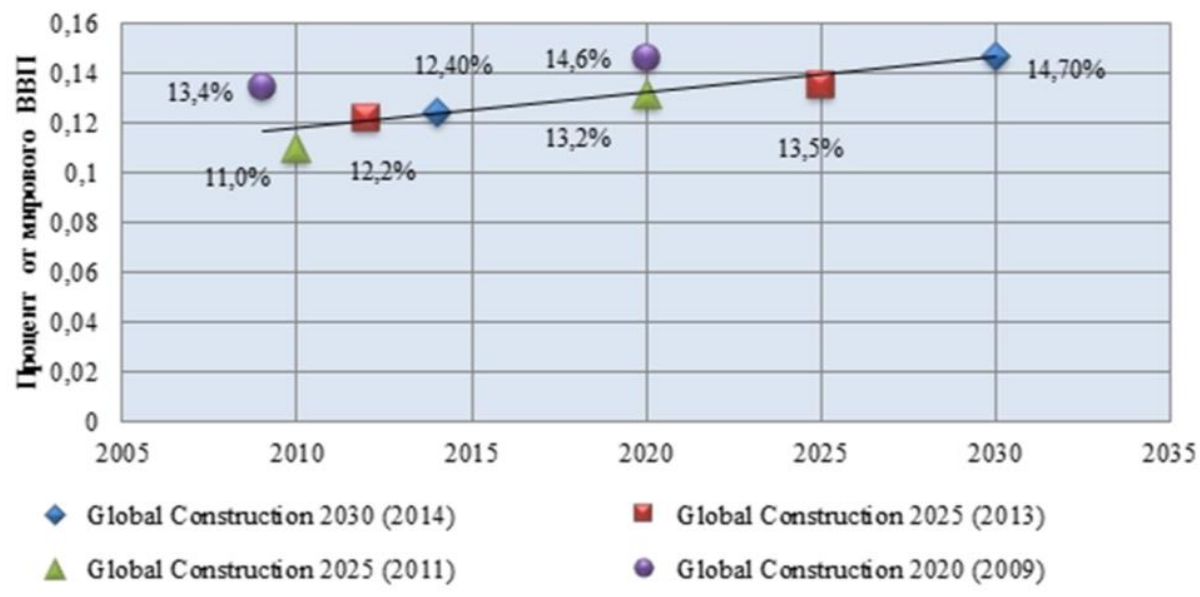

$\Delta$ Global Construction 2025 (2011)

- Global Construction 2020 (2009)

— Линейная (Global Construction 2030 (2014))

Рисунок 2 - Прогнозы изменения удельного веса величины строительства в общем объеме мирового валового внутреннего продукта [2]. 
Вестник Брестского государственного технического университета. 2021

Экономическая конъюнктура приведет к снижению объемов строительного рынка в среднесрочной перспективе в странах Западной Европы по прогнозу, по сравнению с пиком, в 2007 году. Финансовые сложности, которые испытывают правительства ряда европейских стран (Италия, Испания, Греция, Португалия), делают невозможными значительные инвестиции в объекты инфраструктуры в регионе.

Важнейшие фракторы, определяющие развитие европейского рынка строительных услуг в долгосрочной перспективе, - влияние антропогенных климатических изменений на структуру строительства. Планируется увеличить объемы работ по ремонту и реконструкции промышленных зданий и инженерных сооружений (для сокращения энергопотребления и уменьшения парниковых выбросов). Снижение числа лиц трудоспособного возраста к 2025 г. уменьшит спрос на европейском рынке офисной и складской недвижимости, других зданий, а сектор строительства объектов социальной инфраструктуры (больницы, клиники и др.) увеличится по мере старения населения и повышения социальных стандартов.

В странах Евросоюза в 90-х гг. прошлого века созданы промышленные и инфраструктурные объекты, рынок строительных услуг ожидает медленный рост и усиление конкуренции за осуществление их реконструкции между подрядными организациями.

В перспективе ведущие европейские строительные холдинги, как HOCHTIEF AG (Германия), GRUPO ACS (Испания), VINCI (Франция), STRABAG SE (Австрия) пересмотрят стратегии деятельности в направлении укрепления позиций в сегменте возведения объектов инженерной инфрраструктуры (системы инженерных коммуникаций, водоснабжения и канализации и т. п.), который характеризуется большими перспективами роста. В долгосрочной перспективе в Европе увеличится удельный вес контрактов под ключ с фиксированной ценой при полной ответственности строительных компаний за все стадии проектирования, строительства и обеспечения поставок оборудования.

Строительные ТНК в индустриально развитых странах Евросоюза, предположительно, сконцентрируют основное внимание на стимули- ровании экспорта строительных, инженерных и архитектурных услуг, продвижении капитала в форме прямых инвестиций в ди-намично развивающиеся строительные рынки стран Латинской Америки и Юго-Восточной Азии [2].

\section{Динамика развития мирового строительного рынка}

Анализ мирового опыта в 2017 году показывает, что на строительство в мире затрачено \$214.9 млрд долл., что составило в США - $24 \%$, СССР - 15,5\%, Германии - $8 \%$, Японии - 6,6\%, Франции - 4,9\% и другие $41 \%$, а затраты в строительстве на душу населения - \$58,1. Динамика затрат на строительство в мире за 1970-2019 годы (в настоящее время для проведения анализа доступны данные за 2019 год) приведена в таблице 1.

Анализ динамики данных (таблица 1) показывает, что затраты на строительство увеличились в 22,8 раза и составили 4 693,3 млрд долл. (в текущих ценах). По сравнению с 1970 годом в 2019 году за счет роста численности населения на 4011,7 млн увеличились затраты на строительство на душу населения с 58,1 долл. (1970г.) до на 578.3 долл., т. е. примерно в 10 раз. Минимальные затраты на строительство наблюдались в 1970 году и составляли 214,9 млрд долл., а максимум затрат на строительство в 2019 году (4 908,2 млрд долл.). Доля строительства в экономике максимально составляла 6,9\% (1975 г.), а минимальные значения - 5,4 \% характерны для 2000 2002 годов и 2010 года. Начиная с 2011 года наблюдается положительная динамика доли строительства в экономике (5,5 \%) и к 2019 году она возросла до 5,9\%.

В 2019 году затраты на строительство составляли 4 908,2 млрд долл. и в разрезе стран соответствовали для Китая (20,9 \%), США $(18,2 \%)$, Японии (5,8 \%), Индии (4,1\%), Германии (3,8 \%), и других стран (47,2 \%). Следовательно, максимальные затраты на строительство сосредоточены в Китае.

Мировое строительство ведется в разных сферах таблица 2.

Таблица 1 - Динамика затрат на строительство в мире за 1970-2019 годы

\begin{tabular}{|c|c|c|c|c|}
\hline \multirow[b]{2}{*}{ Годы } & \multicolumn{3}{|c|}{ Затраты на строительство } & \multirow{2}{*}{$\begin{array}{c}\text { Доля } \\
\text { строительства } \\
\text { в экономике, \% }\end{array}$} \\
\hline & $\begin{array}{l}\text { В текущих ценах } \\
\text { (млрд долл.) }\end{array}$ & $\begin{array}{c}\text { На душу населения } \\
\text { (в текущих ценах), долл }\end{array}$ & $\begin{array}{c}\text { В постоянных ценах } \\
1970 \text { года (млрд долл.) }\end{array}$ & \\
\hline $1970-1971$ & $214,9 / 241,2$ & $58,1 / 63,9$ & $214,9 / 219,4$ & $6,5 / 6,7$ \\
\hline 1972-1973 & $284,2 / 346,7$ & $73,8 / 88,3$ & $228,8 / 237,3$ & $6,8 / 6,8$ \\
\hline $1974-1975$ & $384,9 / 442,2$ & $96,2 / 108,5$ & $232,9 / 231,3$ & $6,7 / 6,9$ \\
\hline 1976-1977 & $475,5 / 530,7$ & $114,5 / 125,5$ & $240,8 / 245,6$ & $6,8 / 6,8$ \\
\hline 1978-1979 & $636,8 / 727,7$ & $148,0 / 166,2$ & $255,8 / 259,3$ & $6,9 / 6,8$ \\
\hline 1980-1981 & $804,1 / 799,0$ & $180,5 / 176,2$ & $257,6 / 253,1$ & $6,7 / 6,5$ \\
\hline 1982-1983 & $760,6 / 746,9$ & $164,8 / 159,0$ & $247,7 / 246,2$ & $6,2 / 6,0$ \\
\hline 1984-1985 & $746,0 / 755,6$ & $156,0 / 155,2$ & $251,1 / 259,9$ & $5,8 / 5,7$ \\
\hline 1986-1987 & $907,0 / 1039,2$ & $183,0 / 205,8$ & $266,3 / 276,1$ & $6,0 / 6,1$ \\
\hline 1988-1989 & $1190,0 / 1251,3$ & $231,4 / 239,0$ & $293,5 / 306,4$ & $6,2 / 6,2$ \\
\hline 1990-1991 & $1383,6 / 1410,3$ & $259,8 / 260,5$ & $310,7 / 302,1$ & $6,3 / 6,1$ \\
\hline 1992-1993 & $1467,4 / 1510,8$ & $266,9 / 270,7$ & $299,3 / 300,36$ & $5,9 / 6,0$ \\
\hline 1994-1995 & $1613,2 / 1721,6$ & $284,9 / 299,8$ & $307,5 / 307,8$ & $6,0 / 6,0$ \\
\hline 1996-1997 & $1739,9 / 1673,1$ & $298,8 / 283,4$ & $317,1 / 319,9$ & $5,8 / 5,5$ \\
\hline 1998-1999 & $1649,2 / 1711,9$ & $275,6 / 282,3$ & $323,6 / 328,9$ & $5,5 / 5,5$ \\
\hline $2000-2001$ & $1744,9 / 1732,2$ & $284,1 / 278,4$ & $335,4 / 336,3$ & $5,4 / 5,4$ \\
\hline $2002-2003$ & $1778,7 / 2009,8$ & $282,3 / 315,0$ & $337,5 / 345,4$ & $5,4 / 5,4$ \\
\hline $2004-2005$ & $2301,5 / 2525,6$ & $356,3 / 386,2$ & $359,6 / 370,7$ & $5,5 / 5,6$ \\
\hline $2006-2007$ & $2793,2 / 3190,0$ & $421,8475,8$ & $385,9 / 399,3$ & $5,7 / 5,8$ \\
\hline $2008-2009$ & $3466,9 / 3251,9$ & $510,8 / 473,3$ & $397,5 / 387,4$ & $5,7 / 5,6$ \\
\hline $2010-2011$ & $3426,7 / 3837,6$ & $492,7 / 545,1$ & $390,7 / 400,3$ & $5,4 / 5,5$ \\
\hline $2012-2013$ & $3971,4 / 4115,9$ & $557,5 / 570,9$ & $415,5 / 429,8$ & $5,6 / 5,6$ \\
\hline $2014-2015$ & $4272,6 / 4054,3$ & $585,8 / 549,5$ & $445,5 / 458,7$ & $5,7 / 5,7$ \\
\hline $2016-2017$ & $4138,4 / 4450,6$ & $554,6 / 589,8$ & $473,1 / 488,0$ & $5,7 / 5,8$ \\
\hline $2018-2019$ & $4790,2 / 4908,2$ & $627,9 / 636,4$ & $501,8 / 511,7$ & $5,8 / 5,9$ \\
\hline $2010-2011$ & $3426,7 / 3837,6$ & $492,7 / 545,1$ & $390,7 / 400,3$ & $5,4 / 5,5$ \\
\hline $2012-2013$ & $3971,4 / 4115,9$ & $557,5 / 570,9$ & $415,5 / 429,8$ & $5,6 / 5,6$ \\
\hline 2014-2015 & $4272,6 / 4054,3$ & $585,8 / 549,5$ & $445,5 / 458,7$ & $5,7 / 5,7$ \\
\hline 2016-2017 & $4138,4 / 4450,6$ & $554,6 / 589,8$ & $473,1 / 488,0$ & $5,7 / 5,8$ \\
\hline $2018-2019$ & $4790,2 / 4908,2$ & $627,9 / 636,4$ & $501,8 / 511,7$ & $5,8 / 5,9$ \\
\hline
\end{tabular}

Примечание: составлено автором на основе [3] 
Таблица 2 - Суммарная экспортная выручка ТОП 250 лидирующих строительных ТНК в 2019 году

\begin{tabular}{|l|c|c|}
\multicolumn{1}{|c|}{ Сореры строительства } & \multicolumn{2}{|c|}{ Единицы измерения } \\
\cline { 2 - 3 } & млрд долл. & \% \\
\hline Строительство заводов по утилизации опасных отходов & 525 & 0,01 \\
\hline Телекоммуникационное строительство & 7842 & 1,67 \\
\hline Коммунальное строительство & 7949 & 1,69 \\
\hline Строительство производств & 10822 & 2,29 \\
\hline Строительство объектов водоснабжения & 13904 & 2,96 \\
\hline Прочие виды строительства & 26448 & 5,59 \\
\hline Индустриальное строительство & 16048 \\
\hline Энергетическое строительство & 48557 & 3,39 \\
\hline Жилищное и гражданское строительство & 123457 & 10,28 \\
\hline Строительство объектов топливного комплекса & 26,12 \\
\hline Строительство транспортной инфраструктуры & 70934 & 15,00 \\
\hline Всего & 146582 & 31,00 \\
\hline
\end{tabular}

Примечание: составлено автором на основе [4].

Таким образом, наибольшую суммарную экспортную выручку ТОП 250 лидирующих строительных ТНК в 2019 году составляет строительство транспортной инсрраструктуры - 31 \% и жилищное строительство $26,12 \%$, а 42,88 \% приходится на другие сфреры строительства.

Существенное отличие наблюдается в строительной отрасли по регионам рисунок 3.

В разрезе регионов мира в 1970 году рейтинг в Европе составлял 49,9\%, в то время как в Азии только 12,9\%. Ситуация в 2019 году изменилась, что связано с ростом региональной экономики стран. В Азиатском регионе рейтинг составил $43,8 \%$, (соответствует рейтингу Европы 49,9 \% в 1970 году).

Затраты на строительство по рейтингу мировой строительной отрасли по регионам в 2019 году составляют в: Азии - 2151,6 млрд долл. Америке - 1357,7 млрд долл., Европе - 1124,6 млрд долл., Африке 158,8 млрд долл., Океании - 115,6 млрд долл.

По рейтингу в разрезе стран можно выделить 10 стран, занимающих первые места. Первое место принадлежит Китаю, а 10 - России.

В рейтинге страны ЕАЭС занимают следующие места: Казахстан - 56 место (10,0 млрд долл.) составляет 0,20\%; Беларусь 79 место (3,5 млрд долл.) составляет 0,072 \%; Армения - 126 место (0,84 млрд долл.) составляет 0,017\%; Кыргызстан - 127 место (0,82 млрд долл.) составляет 0,017 \%.

Крупнейшими участниками рынка строительных услуг являются рынки Азиатского региона (страны: Китай, Япония, Индонезия). Высокая численность населения в этих странах определяет направления инфраструктурного строительства. В 2019 году строительные компании Китая являются мировыми лидерами. Причина успеха заключается во внедрении масштабной программы по строительству инсрраструктуры в Китае.
Эксперты рассматривают Китай как строительный рынок с наибольшим потенциалом роста, который поддерживается за счет высоких темпов экономического роста. Китай поддерживает высокие темпы строительства внутри страны и выход на зарубежные рынки, вытесняя конкурентов.

Процессы глобализации в строительной отрасли характеризуются: ростом влияния ТНК на мировом и на национальных строительных рынках, вызывающим усиление конкуренции; повышением мобильности рабочей силы, занятой в строительном производстве и смежных отраслях; формированием мирового информационного, научного и образовательного пространства в сфере строительства.

Международные рейтинги выделяют 250 крупнейших строительных компаний и компаний-экспортеров, значительная часть выручки которых формируется от зарубежных (экспортных) контрактов. Рейтинг мировой строительной отрасли по регионам показывает приоритет Китая в строительной отрасли. Поэтому в качестве инноваций в условиях цифровой трансформации в Китае для строительства используются новые строительные материалы и технологии [5-8].

Компании Xinjiang Communications Construction Group Co., Ltd, разработали недорогой цементный бетон с использованием натуральной почвы, который поможет вдвое сократить стоимость и сроки строительства, позволяющий использовать его в инфраструктурном строительстве автомобильных дорог, железных дорог и аэропортов, сельском хозяйстве, лесном хозяйстве, охране водных ресурсов, электроэнергетике и горнодобывающих проектах (производство планирует начать в 2021 году).

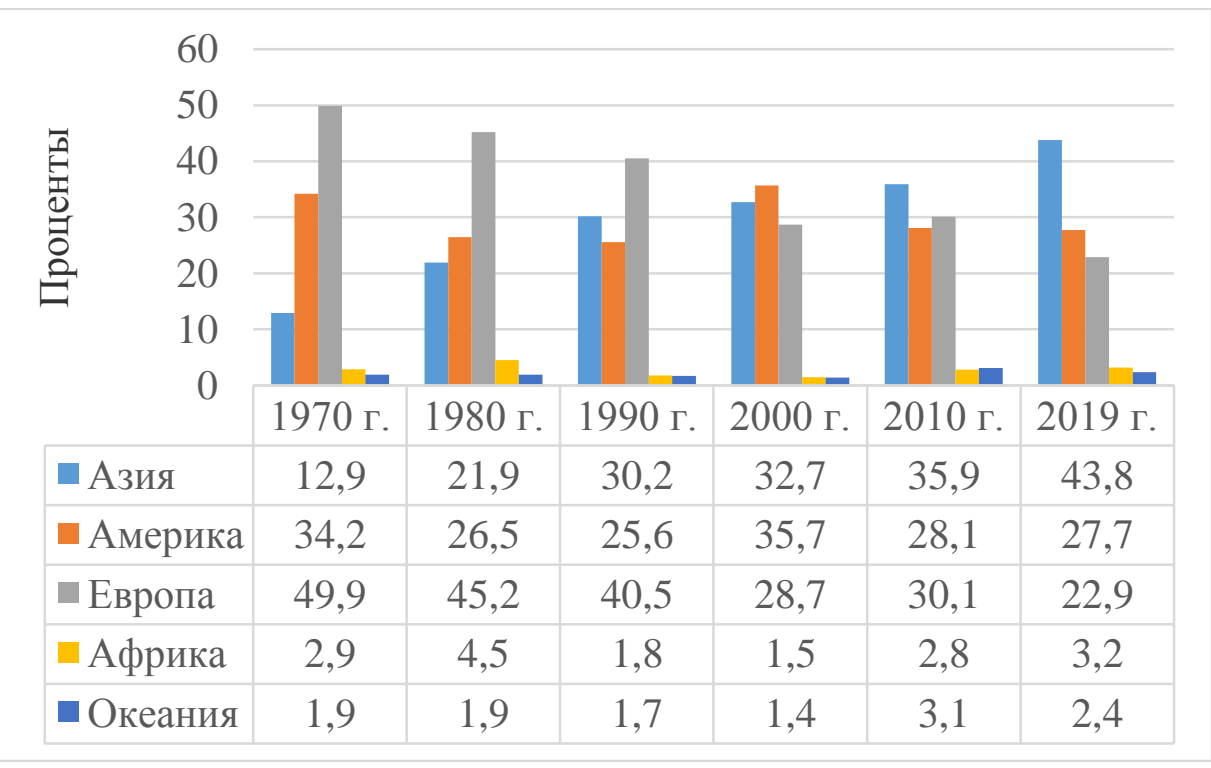

Рисунок 3 - Рейтинг в мировой строительной отрасли по регионам

Примечание: составлено автором на основе [3] 
Вестник Брестского государственного технического университета. 2021

Появилась технология, позволяющая строить многоэтажные дома из плит CTS (Core Tubular Stainless), которые представляют прочный материал из двух панелей, скрепленных стержневыми трубами, который в 10 раз легче бетона, а его антикоррозийные свойства в 100 раз эффективнее, чем у углеродистой стали. Это обеспечивает долговечность материала и устойчивость к землетрясениям. Технологию строительная индустрия позаимствовала у авиационной промышленности, в которые подобные плиты использовались для производства космических капсул. Однако в авиации плиты имели сотовую конструкцию, что делало их производство крайне дорогим. В 2016 году компания BSB нашла выход, заменив соты круглыми трубами и значительно уменьшив стоимость производства. В 2018 компания изобрела уникальную печь, способную массово производить CTS-плиты

На сегодняшний день BSB поставило производство CTS-плит на поток. В 2018 году компания смогла построить 4-этажное жилое здание всего за ночь. Позднее компания возвела 57-этажный дом за 19 дней. На данный момент BSB занимается строительством башни Sky City в китайском городе Чанша, которая должна стать самым высоким зданием в мире.

При использовании технологии модульного строительства за 10 дней построена больница для зараженных коронавирусом в Хошэньшань, рассчитанная на 1000 коек. Производство напоминает сборку конструктора, обусловленую высоким уровнем унификации комплектующих. Технологии модульного строительства в Китае используется и в жилищном строительстве, но из-за шаблонности конструкций здания города лишаются уникальности.

Китай внедрил цифровую технологию Building Information Modelling (BIM) в строительство в 2002 году (в мире она внедрена в 1986 году). Китай является лидером по использованию и развитию BIM и позволяет создавать объекты сложной конструкции и формь (Phoenix Media Center в Пекине), построенные при помощи этой технологии. Форма здания напоминает знаменитую «ленту Мёбиуса», а внешняя оболочка центра состоит из 3800 стеклянных панелей различных размеров. В 2017 году здание получило награду «Outstanding Structure Award» от Международной ассоциации по проектированию мостов и инженерных конструкций.

Китай - первая страна в мире, начавшая использовать технологии 3D-печати для строительства зданий. Эксперты утверждают, что за этой технологией будущее и в будущем 3D-печать станет основным методом строительства. Среди основных достоинств технологии выделяют скорость, экологичность, минимизацию убытков.

Компания Winsun уже успела пройти путь от небольших неказистых домиков до целых жилых кварталов в пригороде Сучжоу. В качества материала для строительства компания использует утилизированный строительный и промышленный мусор, при этом стоимость одного пятиэтажного дома площадью в 200 квадратных метров составляет всего 4800 долларов. В данный момент Winsun оказывает помощь в предотвращении распространения пандемии коронавируса: компании удалось изготовить 15 изоляторов для больных COVID-19 с душевыми и эко-туалетами всего за 1 день.

Технологию компания держит в секрете: любая съемка на территории цеха компании (который, кстати, тоже был произведен с помощью 3D-печати) запрещена, доступ к самому принтеру имеет ограниченное количество человек.

Несмотря на преимущества 3D-печати на нем невозможно производить сложные архитектурные конструкции (ограничиваясь простыми геометрическими формами). Проблемой остается стоимость и сложность создания принтера, но многие страны проявляют интерес к этой технологии строительства [9].

\section{Заключение}

Проведенные исследования показали, что в перспективе до 2035 года планируется положительная динамика развития мировой строительной отрасли. За период с 1970 по 2019 годы изучена динамика изменения развития строительной отрасли по регионам мира. В 2019 году в рейтинге мировой строительной отрасли ведущее место принадлежит Китаю, который использует новые строительные материалы и технологии. По экспертным оценкам Китай строительный рынок с наибольшим потенциалом роста, который поддерживается за счет высоких темпов роста экономики. Китай поддерживает высокие темпы строительства внутри страны и выход на зарубежные рынки, вытесняя конкурентов.

\section{Список цитированных источников}

1. Доклад о цифровой экономике - 2019. Издание $\mathrm{OOH}$, опубликовано Конференцией ООН по торговле и развитию [Электронный ресурс]. - Режим доступа: https: // unctad .org / en /PublicationsLibrary/der2019_overview_ru.pdf. - Дата доступа: 10.01.2020.

2. Обзор развития мирового строительного рынка [Электронный ресурс]. - Режим доступа: https://budexport.by/world_market.php. - Дата доступа: 8.01.2021.

3. Строительство мира, 1970-2019 [Электронный ресурс]. - Режим доступа: https://be5.biz/makroekonomika/construction/world.html. Дата доступа: 7.01.2021.

4. The Top 250 International Contractors 2020 // ENR: Engineering News Record. McGraw-Hill Companies [Электронный ресурс]. 2020. - Режим доступа: http://enr.construction.com. - Дата доступа: 5.01 .2021$.

5. Модульное строительство в Китае [Электронный ресурс]. - Режим доступа: https://zen.yandex.ru/media/searchbiznes/modulnoestroitelstvo-v-kitae-5e70d87e8cd2837a6596f864. - Дата доступа: 2.01.2021.

6. Скоростные стройки по-китайски: в чем их секрет [Электронный ресурс]. - Режим доступа: https://topwar.ru/167146-skorostnyestrojki-po-kitajski-v-chem-ih-sekret.html. - Дата доступа: 5.01.2021.

7. Цифровой рынок Китая: что происходит с технологиями Поднебесной? [Электронный ресурс]. - Режим доступа: https://thesteppe.com/tehnologii/cifrovoy-rynok-kitaya-chto-proishodit-stehnologiyami-podnebesnoy\#. - Дата доступа: 6.01.2021.

8. Передовые технологии в строительстве. Опыт Китая. [Электронный ресурс]. - Режим доступа: https://www.stroytrans.info/stroychina-11904.html. - Дата доступа: 8.01.2021.

9. Топ инновационных строительных технологий Китая [Электронный ресурс]. - Режим доступа: https://raspp.ru/business_news/topchinese-technologies/. - Дата доступа: 8.01.2021.

\section{References}

1. Doklad o cifrovoj ekonomike - 2019. Izdanie OON, opublikovano Konferenciej OON po torgovle i razvitiyu [Elektronnyj resurs]. - Rezhim dostupa: https: // unctad .org / en /PublicartionsLibrary/der2019_overview_ru.pdf. - Data dostupa: 10.01.2020.

2. Obzor razvitiya mirovogo stroitel'nogo rynka [Elektronnyj resurs]. Rezhim dostupa: https://budexport.by/world_market.php. - Data dostupa: 8.01.2021.

3. Stroitel'stvo mira, 1970-2019 [Elektronnyj resurs]. - Rezhim dostupa: https://be5.biz/makroekonomika/construction/-world.html. - Data dostupa: 7.01.2021.

4. The Top 250 International Contractors 2020 // ENR: Engineering News Record. McGraw-Hill Companies [Elektronnyj resurs]. - 2020. Rezhim dostupa: http://enr.construction.com. - Data dostupa: 5.01.2021.

5. Modul'noe stroitel'stvo v Kitae [Elektronnyj resurs]. - Rezhim dostupa: https://zen.yandex.ru/media/searchbiznes/-modulnoe-stroitelstvov-kitae-5e70d87e8cd2837a6596f864. - Data dostupa: 2.01.2021.

6. Skorostnye strojki po-kitajski: v chem in sekret [Elektronnyj resurs]. Rezhim dostupa: https://topwar.ru/167146-skorostnye-strojki-pokitajski-v-chem-ih-sekret.html. - Data dostupa: 5.01.2021.

7. Cifrovoj rynok Kitaya: chto proiskhodit s tekhnologiyami Podnebesnoj? [Elektronnyj resurs]. - Rezhim dostupa: https://thesteppe.com/tehnologii/cifrovoy-rynok-kitaya-chto-proishodit-stehnologiyami-podnebesnoy\#. - Data dostupa: 6.01.2021.

8. Peredovye tekhnologii v stroitel'stve. Opyt Kitaya. [Elektronny] resurs]. - Rezhim dostupa: https://www.stroytrans.info/ᄀstroychina11904.html. - Data dostupa: 8.01.2021.

9. Top innovacionnyh stroitel'nyh tekhnologij Kitaya [Elektronnyj resurs]. Rezhim dostupa: https://raspp.ru/business_news/top-chinese-technologies/. - Data dostupa: 8.01.2021.

Материал поступил в редакцию 11.02.2021 